\title{
Síndrome de Burnout: um estudo com professores de Educação Física
}

\author{
Edilene Cunha Sinott* \\ Mariângela da Rosa Afonso** \\ José Antonio Bicca Ribeiro*** \\ Gelcemar Oliveira Farias ****
}

\begin{abstract}
Resumo: A docência tem, como atributo, o contato direto e intenso com pessoas, característica favorável ao desenvolvimento da Síndrome de Burnout. Este estudo descritivo tem por objetivo verificar a presença dessa síndrome nos professores de Educação Física das escolas municipais da cidade de Pelotas/RS. Os dados revelam que $60,6 \%$ dos professores estavam com alta exaustão emocional; $22,3 \%$ com alta despersonalização; $34,0 \%$ com baixa realização profissional. Os índices sinalizam a presença da síndrome em $8,5 \%$ deles. Os resultados indicam a eminência da atenção dos gestores para a implementação e o cumprimento de políticas públicas na prevenção de doenças que acometem professores.
\end{abstract}

Palavras-chave: Síndrome de Burnout. Professores. Educação Física.

\section{INTRODUÇão}

$\mathrm{O}$ avanço tecnológico provocou mudanças tanto no processo produtivo, as quais possibilitaram o aumento dos lucros, quanto na vida das pessoas, trazendo impactos à saúde do trabalhador, com diferentes manifestações físicas e psíquicas. Nesse contexto, a educação não ficou alheia às novidades introduzidas no mundo do trabalho, causadoras de exaustão física e emocional, insatisfação

\footnotetext{
*Professora da Rede Municipal, Pelotas, RS, Brasil. E-mail: lenesinott@yahoo.com.br **Professora do Programa de Pós-Graduação em Educação Física, Escola de Educação Física, Universidade Federal de Pelotas, Pelotas, RS, Brasil. E-mail: cafonso@terra.com.br ***Mestrando do Programa de Pós-Graduação em Educação Física, Escola de Educação Física, Universidade Federal de Pelotas, Pelotas, RS, Brasil. E-mail: zeantonio_bicca@ hotmail.com

****Professora, Universidade do Estado de Santa Catarina, Florianópolis, SC, Brasil. E-mail: fariasgel@hotmail.com
} 
profissional, absenteísmo e especificamente doenças oriundas do exercício profissional docente, devido à complexidade do processo laboral característico dessa profissão.

Dentre as consequências ocasionadas por situações ocupacionais, está a Síndrome de Burnout, descrita, em 1974, pelo psiquiatra americano Herbert Freudenberger (MASLACH; SCHAUFELI; LEITER, 2001). A Síndrome de Burnout ou Síndrome do Esgotamento Profissional, como referida na investigação de Santini (2004), é uma reação à tensão emocional crônica, gerada pelo trabalho exercido em contato direto e excessivo com as pessoas. Segundo Maslach e Jackson (1981), esta síndrome apresenta por três dimensões: exaustão emocional (dimensão identificada pela sensação de exaustão física e emocional); despersonalização (representa a dimensão do contexto interpessoal da Síndrome de Burnout e referese a atitudes de distanciamento emocional); realização profissional (corresponde à dimensão da auto avaliação da síndrome e refere-se ao sentimento de impotência, à baixa produtividade no trabalho e ao descontentamento pessoal) (MASLACH; JACKSON, 1981, CODO; VASQUES-MENEZES, 1999, MASLACH; SHAUFELI; LEITER, 2001, BENEVIDES-PEREIRA, 2002).

A Síndrome de Burnout tem sido foco de investigações com professores da educação básica (CARLOTTO; PALAZZO, 2006, MAZON; CARLOTTO; CÂMARA, 2008), com professores de Educação Física (SANTINI, 2004; SANTINI; MOLINA NETO, 2005; MOREIRA et al., 2009); com profissionais da área da saúde (MUROFUSE; ABRANCHES; NAPOLEÃO, 2005, TIRONI et al., 2009); com acadêmicos (CHRISTOFOLETTI et al., 2007), pois ela acomete profissionais das mais variadas ocupações.

A Síndrome de Burnout acomete o indivíduo quando esse apresenta baixa expectativa frente à realização profissional, alta despersonalização e alta exaustão emocional. Benevides-Pereira (2002) salienta que o sintoma típico da síndrome é a sensação de esgotamento físico e emocional que se reflete em atitudes negativas, como absenteísmo, agressividade, isolamento, mudanças bruscas

Movimento, Porto Alegre, v. 20, n. 2, p. 519-539, abr./jun. de 2014. 
de humor, irritabilidade, dificuldade de concentração, lapsos de memória, ansiedade, depressão, pessimismo e baixa autoestima. Ainda são descritos: dores de cabeça, sudorese, fadiga constante, imunodeficiência, transtornos cardiovasculares, distúrbios dos sistemas respiratórios e gastrintestinais, disfunções sexuais, hipertensão, dores musculares, insônia e crises de asma.

O professor idealista, entusiasmado com a docência, é mais vulnerável à Síndrome de Burnout, pois seu comprometimento com o trabalho o faz envolver-se intensamente, sentindo-se frustrado quando não percebe retorno desse esforço. $\mathrm{O}$ alto nível de expectativa que o docente tem e que não é preenchido, também pode se associar à síndrome (MASLACH; JACKSON, 1984).

Evidenciando riscos a que docentes com Síndrome de Burnout estão expostos, o estudo de Levy, Nunes Sobrinho e Souza (2009) revelou que docentes acometidos pela síndrome são mais vulneráveis a sofrer agressões físicas em sala de aula. No que concerne à Educação Física, peculiaridades importantes, vivenciadas cotidianamente, como o desenvolvimento das aulas práticas, realizadas nos mais diversos espaços, na maioria das escolas públicas, acentuam o nível de estresse do profissional. Além disso, condições laborais insatisfatórias - calor, frio, ruídos excessivos, precária higienização e limitações de espaços físicos - também podem levar à Síndrome de Burnout (GIL-MONTE; PEIRÓ, 1997, BENEVIDES-PEREIRA, 2002).

$\mathrm{O}$ estudo de Rodrigues, Figueiredo e Andrade Filho (2012), que trata das relações sócio profissionais no ambiente escolar, afirma a importância do estabelecimento de relações que fortaleçam a construção da identidade docente, de modo a qualificar a intervenção profissional. Nesse sentido, Silva e Afonso (2012) reportam a ideia de que o estilo de vida digno do educador contribui no processo de aprendizagem do educando.

Justifica-se, portanto, a realização deste estudo, com o objetivo de investigar a Síndrome de Burnout em professores de Educação Física das escolas da rede municipal de Pelotas/RS,

Movimento, Porto Alegre, v. 20, n. 2, p. 519-539, abr.jun. de 2014. 
pois, na medida em que se amplia o entendimento desse fenômeno, identificando etapas, dimensões, estressores e variáveis com associações mais significativas, torna-se possível buscar formas de prevenir, minimizar ou até mesmo barrar essa síndrome, auxiliando tanto o docente, em sua qualidade de vida laboral, como os demais envolvidos no processo educativo.

\section{Procedimentos metodológicos}

Este estudo trata-se de uma pesquisa descritiva com abordagem quantitativa dos dados (MATTAR, 1999, THOMAS; NELSON, 2002, GIL, 2007). De um universo de 118 professores de Educação Física, vinculados à rede pública municipal de Pelotas, participaram do estudo 94 docentes, selecionados a partir dos seguintes critérios de inclusão: a) ser professor de Educação Física da rede municipal; b) atuar em escolas urbanas; c) estar em exercício da docência e/ou na equipe diretiva ou demais setores da escola. Os critérios de exclusão foram: a) estar afastada por licença-maternidade; b) realizar pesquisa de interesse deste estudo.

Como ilustrado na Figura 1, dos professores de Educação Física participantes do estudo: 34 eram do sexo masculino e 60 do sexo feminino; 44 docentes tinham idade até 39 anos e 50, idade igual ou superior a 40 anos; 45 possuíam somente formação inicial em Educação Física e 49 possuíam curso de pós-graduação lato ou stricto senso; a renda salarial ultrapassou 6 salários mínimos para 33 professores e 61 docentes recebiam até 5 salários; 51 respondentes eram casados e 43 informaram outra categoria (solteiro, divorciado, união estável ou viúvo).

Para a coleta das informações, foram utilizados dois questionários: um destinado à coleta de dados sociodemográficos dos professores, e outro nomeado Maslach Burnout Inventory (MBI) de Maslach e Jackson (1986), adaptado pelo Grupo de Estudos e Pesquisas sobre Estresse e Burnout. O Maslach Burnout Inventory é composto por 22 afirmações, acompanhadas por escala Likert de sete pontos, na qual, zero corresponde a 'nunca' e seis a 'todos os

Movimento, Porto Alegre, v. 20, n. 2, p. 519-539, abr./jun. de 2014. 
dias' (nunca, uma vez por ano, uma vez ao mês, algumas vezes ao mês, uma vez por semana, algumas vezes por semana, todos os dias).

Figura 1 - Professores de Educação Física participantes do estudo

\begin{tabular}{|c|c|c|c|}
\hline \multicolumn{4}{|c|}{ VARIÁVEIS SOCIODEMOGRÁFICAS } \\
\hline VARIÁVEIS & CATEGORIAS & $\mathbf{N}$ & $(\%)$ \\
\hline \multirow{2}{*}{ Sexo } & Masculino & 34 & 36,2 \\
\hline & Feminino & 60 & 63,8 \\
\hline \multirow{2}{*}{ Idade } & Até 39 anos & 44 & 46,8 \\
\hline & Igual ou superior a 40 anos & 50 & 53,2 \\
\hline \multirow{2}{*}{ Estado civil } & Casado & 51 & 54,3 \\
\hline & Outros & 43 & 45,7 \\
\hline \multirow{2}{*}{ Renda familiar* } & Até 5 salários & 61 & 64,9 \\
\hline & Igual ou superior a 6 salários & 33 & 35,1 \\
\hline \multirow{2}{*}{ Formação } & Graduação & 45 & 47,9 \\
\hline & Pós-graduação & 49 & 52,1 \\
\hline
\end{tabular}

*Em salários-mínimos

Fonte: Elaborado pelos autores

O instrumento foi estruturado a partir de três dimensões, que buscam identificar as manifestações da Síndrome de Burnout exaustão emocional, despersonalização, realização profissional - sendo categorizadas em baixa, média e alta. Pontuações altas nas dimensões exaustão emocional e despersonalização e baixa pontuação na dimensão realização profissional representam maior incidência da Síndrome de Burnout (MASLACH; JACKSON, 1981, MASLACH; JACKSON, 1986, BENEVIDES-PEREIRA, 2001). A Figura 2 apresenta a escala de análise com as pontuações máximas e mínimas para cada dimensão.

A coleta de dados ocorreu após aprovação do Comitê de Ética da Escola Superior de Educação Física da Universidade Federal de Pelotas (015/2011 de 06/10/2011). Ressalte-se que a participação dos docentes ficou condicionada à sua assinatura do Termo de Consentimento Livre e Esclarecido.

Movimento, Porto Alegre, v. 20, n. 2, p. 519-539, abr.jun. de 2014. 
Figura 2: Escala de análise do Maslach Burnout Inventory desenvolvida pelo Grupo de Estudos e Pesquisas sobre Estresse e Burnout (GEPEB).

\begin{tabular}{cccc}
\hline \multirow{2}{*}{ DIMENSÕES } & \multicolumn{3}{c}{ PONTOS DE CORTE } \\
\cline { 2 - 4 } & BAIXA & MÉDIA & ALTA \\
\hline Exaustão Emocional (EE) & $0-15$ & $16-25$ & $26-54$ \\
Despersonalização (DE) & $0-02$ & $03-08$ & $09-30$ \\
Realização Profissional (RP) & $0-33$ & $34-42$ & $43-48$ \\
\hline
\end{tabular}

Fonte: GEPEB

Para análise, os dados foram armazenados na planilha do Excel - 2007, as análises estatísticas foram realizadas através do software STATA - 12.0. Adotou-se a estatística paramétrica com nível de significância de $\mathrm{p}<0,05$. O teste do Qui-quadrado foi empregado para verificar a diferença entre as variáveis: sexo, idade, estado civil e formação docente. O teste Exato de Fisher foi utilizado para verificar a diferença estatística na dimensão exaustão emocional com a variável renda familiar.

\section{Resultados}

Como resultado do estudo no que tange à variável sexo (Figura 3), observou-se que, na dimensão exaustão emocional, índices mais elevados foram detectados na alta exaustão, tanto para o sexo masculino $(55,8 \%)$, quanto para o sexo feminino $(63,3 \%)$. Índices acentuados na média despersonalização foram verificados em $41,2 \%$ dos docentes do sexo masculino e em $40 \%$ do feminino. A média realização profissional foi contemplada em $41,2 \%$ dos docentes do sexo masculino e em $50,0 \%$ do feminino.

Como sintetizado na Figura 4, a maioria dos professores do estudo apresentou idade de 40 anos ou mais $(53,2 \%)$, em detrimento a professores com idades até 39 anos (46,8\%). Ambos os grupos apresentaram alta exaustão emocional: até 39 anos 72,7\% e igual ou superior a 40,50\%. Contudo, os docentes com idade até 30 anos manifestaram índices superiores na baixa despersonalização e na baixa realização profissional.

Movimento, Porto Alegre, v. 20, n. 2, p. 519-539, abr./jun. de 2014. 
Figura 3: Dimensões da Síndrome de Burnout e a variável sexo

\begin{tabular}{|c|c|c|c|c|c|}
\hline \multirow{2}{*}{ ÍNDICES } & BAIXA & MÉDIA & ALTA & TOTAL & \multirow{2}{*}{ p* } \\
\hline & n (\%) & n (\%) & n (\%) & n (\%) & \\
\hline \multicolumn{6}{|c|}{ EXAUSTÃO EMOCIONAL } \\
\hline Masculino & $6(17,7)$ & $9(26,5)$ & $19(55,8)$ & $34(100,0)$ & \multirow{3}{*}{$0,551 *$} \\
\hline Feminino & $6(10,0)$ & $16(26,7)$ & $38(63,3)$ & $60(100,0)$ & \\
\hline Total & $12(12,8)$ & $25(26,6)$ & $57(60,6)$ & $94(100,0)$ & \\
\hline \multicolumn{6}{|c|}{ DESPERSONALIZAÇÃO } \\
\hline Masculino & $12(35,3)$ & $14(41,2)$ & $8(23,5)$ & $34(100,0)$ & \multirow{3}{*}{$0,954^{*}$} \\
\hline Feminino & $23(38,3)$ & $24(40,0)$ & $13(21,7)$ & $60(100,0)$ & \\
\hline Total & $35(37,2)$ & $38(40,4)$ & $21(22,3)$ & $94(100,0)$ & \\
\hline \multicolumn{6}{|c|}{ REALIZAÇÃO PROFISSIONAL } \\
\hline Masculino & $11(32,4)$ & $14(41,2)$ & $9(26,5)$ & $34(100,0)$ & \multirow{3}{*}{$0,387^{*}$} \\
\hline Feminino & $21(35,0)$ & $30(50,0)$ & $9(15,0)$ & $60(100,0)$ & \\
\hline Total & $32(34,0)$ & $44(46,8)$ & $18(19,2)$ & $94(100,0)$ & \\
\hline
\end{tabular}

*Teste do Qui-quadrado

Fonte: Elaborado pelos autores

Figura 4: Dimensões da Síndrome de Burnout e a variável idade

\begin{tabular}{|c|c|c|c|c|c|}
\hline ÍNDICES & $\begin{array}{c}\text { BAIXA } \\
\text { n (\%) }\end{array}$ & $\begin{array}{c}\text { MÉDIA } \\
\text { n }(\%)\end{array}$ & $\begin{array}{l}\text { ALTA } \\
\text { n (\%) }\end{array}$ & $\begin{array}{c}\text { TOTAL } \\
\text { n }(\%)\end{array}$ & $\mathbf{p}$ \\
\hline \multicolumn{6}{|c|}{ EXAUSTÃO EMOCIONAL } \\
\hline Até 39 anos & $4(9,1)$ & $8(18,2)$ & $32(72,7)$ & $44(100,0)$ & \multirow{3}{*}{$0,079 *$} \\
\hline Igual ou sup. a 40 anos & $8(16,0)$ & $17(34,0)$ & $25(50,0)$ & $50(100,0)$ & \\
\hline Total & $12(12,8)$ & $25(26,5)$ & $57(60,6)$ & $94(100,0)$ & \\
\hline \multicolumn{6}{|c|}{ DESPERSONALIZAÇÃO } \\
\hline Até 39 anos & $18(40,9)$ & $13(29,6)$ & $13(29,6)$ & $44(100,0)$ & \multirow{3}{*}{$0,098 *$} \\
\hline Igual ou sup. a 40 anos & $17(34,0)$ & $25(50,0)$ & $8(16,0)$ & $50(100,0)$ & \\
\hline Total & $35(37,2)$ & $38(40,4)$ & $21(22,3)$ & $94(100,0)$ & \\
\hline \multicolumn{6}{|c|}{ REALIZAÇÃO PROFISSIONAL } \\
\hline Até 39 anos & $21(47,7)$ & $20(45,5)$ & $3(6,8)$ & $44(100,0)$ & \multirow{3}{*}{$0,004 *$} \\
\hline Igual ou sup. a 40 anos & $11(22,0)$ & $24(48,0)$ & $15(30,0)$ & $50(100,0)$ & \\
\hline Total & $32(34,0)$ & $44(46,8)$ & $18(19,2)$ & $94(100,0)$ & \\
\hline
\end{tabular}

Fonte: Elaborado pelos autores

Movimento, Porto Alegre, v. 20, n. 2, p. 519-539, abr.jun. de 2014. 
Com relação à variável estado civil (Figura 5), constatouse que $54,3 \%$ dos professores são casados e $45,7 \%$ pertencem a outras categorias de estado civil. Constatou-se diferença estatisticamente significativa $(\mathrm{p}=0,032)$, no que se refere à variável estado civil e à dimensão exaustão emocional, destacando altos índices com predominância em docentes casados. Por outro lado, percentuais superiores foram observados em docentes de ambos os grupos etários, na média realização profissional e média despersonalização.

Figura 5: Dimensões da Síndrome de Burnout e a variável estado civil

\begin{tabular}{|c|c|c|c|c|c|}
\hline ÍNDICES & $\begin{array}{c}\text { BAIXA } \\
\text { n (\%) }\end{array}$ & $\begin{array}{c}\text { MÉDIA } \\
\text { n (\%) }\end{array}$ & $\begin{array}{l}\text { ALTA } \\
\text { n (\%) }\end{array}$ & $\begin{array}{c}\text { TOTAL } \\
\text { n (\%) }\end{array}$ & $\mathbf{p}$ \\
\hline \multicolumn{6}{|c|}{ EXAUSTÃO EMOCIONAL } \\
\hline Casados & $8(15,7)$ & $8(15,7)$ & $35(68,6)$ & $51(100,0)$ & \multirow{3}{*}{$0,032^{*}$} \\
\hline Outros & $4(9,3)$ & $17(39,5)$ & $22(51,2)$ & $43(100,0)$ & \\
\hline Total & $12(12,8)$ & $25(26,6)$ & $57(60,6)$ & $94(100,0)$ & \\
\hline \multicolumn{6}{|c|}{ DESPERSONALIZAÇÃO } \\
\hline Casados & $16(31,4)$ & $22(43,1)$ & $13(25,5)$ & $51(100,0)$ & \multirow{3}{*}{$0,422^{*}$} \\
\hline Outros & $19(44,2)$ & $16(37,2)$ & $8(18,6)$ & $43(100,0)$ & \\
\hline Total & $35(37,2)$ & $38(40,4)$ & $21(22,3)$ & $94(100,0)$ & \\
\hline \multicolumn{6}{|c|}{ REALIZAÇÃO PROFISSIONAL } \\
\hline Casados & $17(33,3)$ & $26(51,1)$ & $8(15,7)$ & $51(100,0)$ & \multirow{3}{*}{$0,569^{*}$} \\
\hline Outros & $15(34,9)$ & $18(41,9)$ & $10(23,3)$ & $43(100,0)$ & \\
\hline Total & $32(34,0)$ & $44(46,8)$ & $18(19,2)$ & $94(100,0)$ & \\
\hline
\end{tabular}

Considerando a renda salarial de todos os componentes que integram a família dos professores participantes do estudo (Figura 6), identificou-se que 64,9\% dos docentes recebem até cinco salários-mínimos e 35,1\% recebem seis salários-mínimos ou mais. Assim, os dois grupos de professores, apresentaram alta exaustão salarial, diferente da dimensão despersonalização

Movimento, Porto Alegre, v. 20, n. 2, p. 519-539, abr./jun. de 2014. 
em que os $47,5 \%$ dos professores que perfazem até 5 salários mínimos e 45,5\% dos que perfazem 6 salários mínimos ou mais de renda familiar reportam média despersonalização. No entanto, em relação à dimensão despersonalização, os docentes não manifestaram altos índices, centrando-se 39,2\% dos docentes com renda até 5 salários mínimos na baixa despersonalização e $48,5 \%$ dos docentes com 6 ou mais salários mínimos de renda familiar, na média despersonalização.

Figura 6: Dimensões da Síndrome de Burnout e a variável renda familiar

\begin{tabular}{|c|c|c|c|c|c|}
\hline ÍNDICES & $\begin{array}{c}\text { BAIXA } \\
\text { n (\%) }\end{array}$ & $\begin{array}{c}\text { MÉDIA } \\
\text { n (\%) }\end{array}$ & $\begin{array}{l}\text { ALTA } \\
\text { n (\%) }\end{array}$ & $\begin{array}{c}\text { TOTAL } \\
\text { n (\%) }\end{array}$ & $\mathbf{p}$ \\
\hline \multicolumn{6}{|c|}{ EXAUSTÃO EMOCIONAL } \\
\hline Até $6 \mathrm{~s} . \mathrm{m}$. & $9(14,8)$ & $15(24,6)$ & $37(60,7)$ & $61(100,0)$ & \multirow{3}{*}{$0,740 * *$} \\
\hline $\begin{array}{l}\text { Igual ou sup. a } 6 \\
\text { s. m. }\end{array}$ & $3(9,1)$ & $10(30,3)$ & $20(60,6)$ & $33(100,0)$ & \\
\hline Total & $12(12,8)$ & $25(26,6)$ & $57(60,6)$ & $94(100,0)$ & \\
\hline \multicolumn{6}{|c|}{ DESPERSONALIZAÇÃO } \\
\hline $\begin{array}{l}\text { Até } 5 \text { salários- } \\
\text { mínimos }\end{array}$ & $24(39,3)$ & $22(36,1)$ & $15(24,6)$ & $61(100,0)$ & \multirow{3}{*}{$0,492 *$} \\
\hline $\begin{array}{c}\text { Igual ou superior a } \\
6 \mathrm{~s} . \mathrm{m} \text {. }\end{array}$ & $11(33,3)$ & $16(48,5)$ & $6(18,2)$ & $33(100,0)$ & \\
\hline Total & $35(37,2)$ & $38(40,4)$ & $21(22,3)$ & $94(100,0)$ & \\
\hline \multicolumn{6}{|c|}{ REALIZAÇÃO PROFISSIONAL } \\
\hline $\begin{array}{l}\text { Até } 5 \text { salários- } \\
\text { mínimos }\end{array}$ & $24(39,3)$ & $29(47,5)$ & $8(13,1)$ & $61(100,0)$ & \multirow{3}{*}{$0,093 *$} \\
\hline $\begin{array}{l}\text { Igual ou superior a } \\
6 \text { s. m. }\end{array}$ & $8(24,2)$ & $15(45,5)$ & $10(30,3)$ & $33(100,0)$ & \\
\hline Total & $32(34,0)$ & $44(46,8)$ & $18(19,2)$ & $94(100,0)$ & \\
\hline
\end{tabular}

*Teste do Qui-quadrado; ** Teste do Exato de Fisher Fonte: Elaborado pelos autores

Considerando a variável formação docente (Figura 7), verificou-se que todos os professores participantes do estudo possuem graduação em Educação Física. Desse total, 49

Movimento, Porto Alegre, v. 20, n. 2, p. 519-539, abr.jun. de 2014. 
concluíram cursos de pós-graduação, sendo que 12 apresentam formação lato senso. Foi verificada diferença estatisticamente significativa $(\mathrm{p}=0,028)$ em relação à variável formação e à dimensão despersonalização. Entretanto, a maior concentração de docentes, considerando as demais dimensões, identifica-se na alta exaustão emocional e na média realização profissional.

Figura 7: Dimensões da Síndrome de Burnout e a variável formação

\begin{tabular}{cccccc}
\hline ÍNDICES & $\begin{array}{c}\text { BAIXA } \\
\text { n (\%) }\end{array}$ & $\begin{array}{c}\text { MÉDIA } \\
\text { n (\%) }\end{array}$ & $\begin{array}{c}\text { ALTA } \\
\text { n (\%) }\end{array}$ & $\begin{array}{c}\text { TOTAL } \\
\text { n (\%) }\end{array}$ & p \\
\hline \multicolumn{6}{c}{ EXAUSTÃO EMOCIONAL } \\
\hline Graduação & $5(11,1)$ & $15(33,3)$ & $25(55,6)$ & $45(100,0)$ \\
\hline Pós-graduação & $7(14,3)$ & $10(20,4)$ & $32(65,3)$ & $49(100,0)$ & $0,363^{*}$ \\
\hline Total & $12(12,8)$ & $25(26,6)$ & $57(60,6)$ & $94(100,0)$ \\
\hline \multicolumn{6}{c}{ DESPERSONALIZAÇÃO } \\
\hline Graduação & $23(51,1)$ & $14(31,1)$ & $8(17,8)$ & $45(100,0)$ \\
\hline Pós-graduação & $12(24,5)$ & $24(49,0)$ & $13(26,5)$ & $49(100,0)$ & $0,028^{*}$ \\
\hline Total & $35(37,2)$ & $38(40,4)$ & $21(22,3)$ & $94(100,0)$ \\
\hline \multicolumn{6}{c}{ REALIZAÇÃO PROFISSIONAL } \\
\hline Graduação & $15(33,3)$ & $21(46,7)$ & $9(20,0)$ & $45(100,0)$ \\
\hline Pós-graduação & $17(34,7)$ & $23(46,9)$ & $9(18,4)$ & $49(100,0)$ & $0,977^{*}$ \\
\hline Total & $32(34,0)$ & $44(46,8)$ & $18(19,2)$ & $94(100,0)$ \\
\hline \multicolumn{5}{c}{}
\end{tabular}

*Teste do Qui-quadrado

Fonte: Elaborado pelos autores

No cômputo final da avaliação da Síndrome de Burnout (Figura 8), identificou-se que os docentes apresentam alta exaustão emocional, dado esse que se manifesta na análise de todas as variáveis do estudo. Todavia, grande parte dos professores apresenta-se vinculada ao grupo com média despersonalização $(40,4 \%)$ e média realização profissional $(46,8 \%)$. Por conseguinte, percentuais muito próximos de professores com média $(40,8 \%)$ e baixa despersonalização $(37,2 \%)$ e média $(46,8 \%)$ e baixa realização profissional $(34,0 \%)$ foram identificados no grupo.

Movimento, Porto Alegre, v. 20, n. 2, p. 519-539, abr./jun. de 2014. 
Figura 8 - Dados gerais das dimensões da Síndrome de Burnout

\begin{tabular}{ccccc}
\hline DIMENSÃO & $\begin{array}{c}\text { BAIXA } \\
\text { n (\%) }\end{array}$ & $\begin{array}{c}\text { MÉDIA } \\
\text { n (\%) }\end{array}$ & $\begin{array}{c}\text { ALTA } \\
\text { n (\%) }\end{array}$ & $\begin{array}{c}\text { TOTAL } \\
\text { n (\%) }\end{array}$ \\
\hline Exaustão Emocional (EE) & $12(12,8)$ & $25(26,6)$ & $57(60,6)$ & $94(100,0)$ \\
\hline Despersonalização (DE) & $35(37,2)$ & $38(40,4)$ & $21(22,3)$ & $94(100,0)$ \\
\hline Realização Profissional (RP) & $32(34,0)$ & $44(46,8)$ & $18(19,2)$ & $94(100,0)$ \\
\hline
\end{tabular}

Fonte: Elaborado pelos autores

\section{Dıscussão}

Pelos resultados do estudo identifica-se que a dimensão exaustão emocional demanda índices de preocupação nos professores investigados e que as mulheres apresentaram maiores percentuais nessa dimensão, dados estes que têm respaldo em estudos de Reis et al. (2006) e de Benevides-Pereira; Takahashi; Massanobu (2010, p. 154), os quais identificaram resultados semelhantes. Reis et al. (2006) afirmam que o excesso de trabalho é um dos fatores preponderantes para a exaustão emocional. Considerando que a maioria dos docentes investigados pertence ao sexo feminino, ressalta que a dupla jornada torna ainda mais exaustivo e desgastante o trabalho para o grupo de docentes desse sexo.

A ligeira diferença encontrada, indicando que docentes do sexo masculino tendem a despersonalizar mais do que os do sexo feminino, foi semelhante à encontrada em Gomes et al. (2010), quando investigaram 689 docentes portugueses. Os autores verificaram que homens tendem a despersonalizar mais que mulheres, o que possivelmente ocorre, devido ao fato destas reagirem melhor aos problemas de estresse em relação aos homens. Maslach e Jackson (1985) explicam que a despersonalização é maior em homens, devido ao fato desses apresentarem maior dificuldade em expressar seus sentimentos em comparação às mulheres.

É coerente destacar a necessidade de um olhar atento às condições laborais no contexto de intervenção dos professores. O estudo de Guimarães (2005) revela que a realização profissional é,

Movimento, Porto Alegre, v. 20, n. 2, p. 519-539, abr.jun. de 2014. 
ao mesmo tempo, um aspecto de prazer e de sofrimento no trabalho, sujeito ao impacto dos valores do trabalhador em relação ao seu contexto de intervenção, principalmente no referente às interações sociais estabelecidas no ambiente laboral.

A variável idade em relação à dimensão exaustão emocional demonstra altos índices nos docentes de ambos os conjuntos de faixas etárias. Os docentes com idade mais avançada apresentaram, porém, percentuais menores de alta exaustão emocional, pois, na medida em que os anos avançam, o profissional vai adquirindo maior segurança nas atividades realizadas e, consequentemente, menor vulnerabilidade às tensões laborais (SANTINI, 2004).

Com o avanço da idade, os professores tendem a se sentirem mais realizados profissionalmente e, talvez, a diversificarem suas relações com os pares e a comunidade escolar. Os resultados encontrados evidenciando maior despersonalização em docentes mais jovens buscam entendimento em estudos que defendem esse comportamento como um derivado da inexperiência docente (LEVY; NUNES SOBRINHO; SOUZA, 2009).

Encontrou-se associação positiva entre realização profissional e a variável idade, indicando que os docentes com mais idade possuem maior realização profissional. Este fato pode ser compreendido na medida em que o professor com mais idade consegue mobilizar saberes desenvolvidos a partir de sua vivência, de sua prática pedagógica e do convívio com seus pares, podendo estar mais preparado emocional e pedagogicamente para lidar com certas questões que faltam ao professor com menos idade, que entra na escola logo após a licenciatura e se depara com uma realidade diferente daquela vivida na universidade (TARDIFF, 2000).

Foi perceptível, na análise individual de cada participante do estudo, que somente uma docente não apresenta características da Síndrome de Burnout, apresentando, concomitantemente, baixa exaustão emocional, baixa despersonalização e alta realização profissional. Sugerem-se estudos com a mesma professora, a fim de buscar informações acerca do ambiente, da personalidade, do

Movimento, Porto Alegre, v. 20, n. 2, p. 519-539, abr./jun. de 2014. 
contexto e das demais variáveis que possam fornecer indicadores para compreensão e enfrentamento do Burnout.

Os resultados encontrados revelam que estratégias de devem ser efetivadas pelo órgão dirigente, no intuito de realmente concretizar programas de formação continuada, atendimento especial aos professores em situação de Síndrome de Burnout, buscando a satisfação e a realização profissional do docente. Desta forma, se fazem necessários atenção e apoio aos professores em geral, porém com especial olhar para a acolhida àqueles mais jovens, que se encontram no ciclo de entrada da carreira, de acordo com a classificação profissional proferida por Farias e Nascimento (2012), para que eles exerçam a profissão docente com qualidade, conservando a saúde e minimizando o abandono da carreira.

No concernente à questão familiar, Santini (2004), adverte que a estabilidade afetiva de ser pai e mãe propicia o equilíbrio requerido para resolver situações conflitivas. Entretanto, não é somente a situação familiar a variável associada à Síndrome de Burnout, mas, fundamentalmente, é o lugar ocupado pela família em relação ao trabalho no contexto dos profissionais que priorizam o ensino sobre a própria vida familiar. Por outro lado, o apoio familiar, no que se refere ao trabalho é fundamental como estratégia de enfrentamento à Síndrome de Burnout à Síndrome de Burnout (BENEVIDESPEREIRA; YAMASHITA; TAKAHASHI, 2010). Ressalte-se que, ao ser referido o termo "família", aqui se pressupõem as diferentes formas desta instituição, em seus aspectos históricos e culturais.

Buscando compreender os resultados obtidos quanto à variável renda, fez-se uma análise dos salários. Verificou-se que, em 2009, o salário-base do magistério municipal pelotense, identificado através de contracheque de professor nível II, correspondente à licenciatura plena, como a maioria dos participantes desta pesquisa, com jornada de $20 \mathrm{~h}$ semanais, perfazia o equivalente a $0,67 \%$ de um salário-mínimo federal vigente. Passados quatro anos, constata-se que o salário-base baixou para um valor que corresponde a $0,53 \%$ de um salário-mínimo federal vigente. Considerando o saláriomínimo regional, o percentual se reduz para $0,47 \%$.

Movimento, Porto Alegre, v. 20, n. 2, p. 519-539, abr.jun. de 2014. 
Ao verificarem a qualidade de vida de professores de Educação Física, Silva e Nunes (2009) revelaram que o salário foi o principal fator de insatisfação desses profissionais, seguido por número de alunos por turma; condições de trabalho relacionadas ao espaço físico e a materiais; cobrança de gestores. A insatisfação pelos baixos salários leva a grande maioria dos docentes a buscar pluriempregos, referindo-se a atividades relacionadas à área de formação da Educação Física, como instrução de musculação, preparação física, entre outras, como forma de aumentar a renda da família (SILVA; NUNES, 2009).

A política governamental em relação à valorização docente deveria ser colocada em prática, uma vez que a progressão na carreira, os salários e as condições de trabalho deixam muito a desejar, pondo em risco a saúde física e emocional desses profissionais, o que contribui para o abandono da carreira docente e as sobras de vagas nos cursos de licenciatura e de pedagogia (LEMOS, 2007, MOREIRA et al., 2009, SILVA; LIMA, 2010).

Apesar das dificuldades constantemente identificadas pelos docentes, a formação dos professores de Educação Física vinculados às escolas municipais de Pelotas busca o processo de qualificação profissional, o que deve ser revisto no plano de cargos e salários. Ainda que os profissionais desta rede sejam qualificados, a valorização docente está aquém do esperado, o que leva a compreender os altos índices de exaustão emocional evidenciados nesta investigação. Diversos estudos sinalizam essa variável como indicadora de elevados índices nessa dimensão e mostram que esse fenômeno ocorre devido às altas expectativas ou ao idealismo que o docente tem em relação à sua formação (SANTINI, 2004, GILMONTE; PEIRÓ, 1997).

Os resultados indicam que o nível de graduação mais elevado está associado positivamente com a dimensão despersonalização e a formação profissional, evidenciando que os docentes com maior nível de graduação despersonalizam mais. Essa descoberta pode ser entendida a partir da argumentação de Carlotto (2001) ao dizer

Movimento, Porto Alegre, v. 20, n. 2, p. 519-539, abr.jun. de 2014. 
que o indivíduo apresenta maiores níveis de Burnout quando possui altas discrepâncias entre as expectativas de desenvolvimento profissional e os aspectos reais do seu trabalho.

Para compreender os resultados aqui revelados, buscou-se a legislação municipal alusiva ao Plano de Carreira do Magistério, a qual aborda o incentivo, ou seja, a forma de conferir retribuição pecuniária segundo a qualificação (PELOTAS, 1989). Ocorre que os incentivos referidos na legislação vigente incidem sobre o vencimento, ou seja, sobre o salário básico do professor. A falta de implementação, pelo município de Pelotas, da lei federal que instituiu o piso salarial profissional nacional para os profissionais do magistério público, Lei ${ }^{\circ} 11.738 / 2008$, Brasil (2008), torna irrisória a diferença salarial advinda do incentivo, até mesmo contrária à valorização do trabalho qualificado. Isto tem levado cada vez mais à defasagem salarial essa classe que, para garantir o sustento básico familiar, enfrenta uma jornada desgastante e insalubre de trabalho, mesmo possuindo boa formação, como é o caso dos professores participantes deste estudo (SINOTT; VEIGA; AFONSO, 2012).

É necessário buscar uma nova identidade docente. Nóvoa (1998) alerta para que se ultrapasse a visão de miserabilidade a qual acabou envolvendo os professores interferindo na sua autoestima e, consequentemente, na ação pedagógica docente. Pela análise da dimensão realização profissional verificou-se haver aproximação de resultados entre docentes graduados e pós-graduados.

O resgate da identidade docente, sinalizado por Nóvoa (1998), perpassa as políticas públicas de valorização do trabalho e da formação docente, visando que o profissional sinta-se estimulado a buscar qualificação, sabendo que, além de reforçar a qualidade do ensino, o aprimoramento será revertido em efetiva compensação salarial, possibilitando melhor qualidade de vida, saúde e dignidade docente.

A todas as fragilidades da atividade docente, estão inerentes as condições de trabalho, os baixos salários, as relações interpessoais, a vida familiar, a rotina de transporte, a baixa valorização

Movimento, Porto Alegre, v. 20, n. 2, p. 519-539, abr.jun. de 2014. 
profissional. Certamente, tudo isto causa aflições, angústias, crenças e expectativas, ora concretizadas, ora transformadas em difíceis situações de ordem psicológica e física. Todas essas tensões ocasionam a debilidade no contexto escolar e podem ser denunciantes da Síndrome de Burnout. De fato, os dados deveriam não condicionar nenhum docente a esta síndrome, mas mesmo que um número reduzido, em vista do tamanho da amostra, tenha sido apontado com foco na síndrome, as metas devem ser repensadas para a superação de tal realidade.

\section{Considerações finaIs}

Ao final deste estudo, que abordou a Síndrome de Burnout em professores de Educação Física da rede municipal de Pelotas, concluiu-se terem os docentes apresentado evidências de já estarem acometidos pela síndrome, embora os dados do estudo possam apenas inferir tal situação.

A partir das variáveis investigadas, bem como da avaliação geral da síndrome, a dimensão exaustão emocional foi aquela que apresentou maiores índices. A dimensão despersonalização manteve-se no nível médio nas variáveis estado civil (casados); idade (igual ou superior a 40 anos); formação (pós-graduados); sexo (masculino e feminino); renda familiar (igual ou superior a 6 salários-mínimos). Na associação dessa dimensão com a variável formação foram encontradas diferenças estatísticas significativas, sinalizando que os docentes graduados apresentaram baixa despersonalização, enquanto, nos pós-graduados, esta dimensão manteve-se na média.

No que concerne à dimensão realização profissional, em nenhuma das variáveis investigadas essa dimensão obteve altos índices, apenas surgindo como média nas variáveis renda familiar, sexo, formação, estado civil, idade (igual ou superior a 40 anos).

A idade foi uma variável de destaque, pois os docentes mais jovens apresentaram, com mais evidência, alta exaustão emocional e baixa realização profissional em relação aos professores mais

Movimento, Porto Alegre, v. 20, n. 2, p. 519-539, abr./jun. de 2014. 
velhos. Embora os índices de realização profissional estejam mais altos nos docentes com maior faixa salarial, o estudo não identificou a renda familiar como um fator determinante para a manifestação da síndrome. Esse resultado pode ter ocorrido em função de serem adotadas apenas duas faixas salariais e ter considerado a renda familiar em detrimento à renda individual do docente. Assim, sugerem-se novos estudos com diferentes abordagens para essa variável.

Conclui-se haver necessidade de professores e gestores terem acesso a estudos desta natureza, para que sejam ampliadas informações e se possibilite maior conhecimento acerca da Síndrome de Burnout. Ressalta-se ainda a importância do fomento e do desenvolvimento de políticas públicas que favoreçam o reconhecimento e a valorização da profissão docente. $\mathrm{O}$ cuidado com a saúde do professor é uma emergência.

\begin{abstract}
Burnout syndrome: a study with Physical Education teachers

Abstract: Teaching has as attribute the direct and intense contact with people, a propitious feature to the development of the Burnout Syndrome. This descriptive cross-sectional study aimed to verify the presence of this syndrome in the physical education teachers of public schools of the city of PelotasRS, Brazil, revealing that $60.6 \%$ of teachers were with high emotional exhaustion, $22.3 \%$ with high depersonalization and $34.0 \%$ with low professional fulfillment. In $8.5 \%$ of them, the rates display the presence of the syndrome. The results indicate the urgency of the attention of managers to the implementation and compliance with public policies on prevention of diseases that affect teachers.
\end{abstract}

Keywords: Burnout Syndrome. Teachers. Physical Education. 


Síndrome de Burnout: un estudio con profesores de
Educación Física
Resumen: La enseñanza tiene como condición el contacto
directo e intenso con la gente, característica propicia para el
desarrollo del Síndrome de Burnout. Este estudio descriptivo
y transversal tuvo como objetivo verificar la presencia de
este síndrome en los profesores de Educación Física de las
escuelas municipales de la ciudad de Pelotas/RS, que revela
que el $60,6 \%$ de los profesores estaban en alto agotamiento
emocional, el $22,3 \%$ con despersonalización alta y el $34.0 \%$
con baja realización profesional; en el $8,5 \%$ de ellos, los
índices indican la presencia del síndrome. Los resultados
indican la urgente atención de los administradores para
la aplicación y ejecución de las políticas públicas en la
prevención de enfermedades que afectan a los docentes.
Palabras-clave: Síndrome de Burnout. Profesores.
Educación Fisica.

\section{REFERÊNCIAS}

ANTONIAZZI, Adriane Scomazzon et al. O conceito de copping: uma revisão teórica. Estudos de Psicologia, Natal, v. 3, n. 2, p. 273-294, 1998. Disponível em <http://www.scielo.br/pdf/epsic/v3n2/a06v03n2.pdf> Acesso em: 15 nov. 2012.

ASAIAG, Paulo Eduardo et al. Avaliação da qualidade de vida, sonolência diurna e Burnout em médicos residentes. Revista Brasileira de Educação Médica, Rio de Janeiro, v. 34, n. 3, p. 422-429, 2010.

BENEVIDES PEREIRA, Ana Maria Teresa. MBI - Maslach Burnout Inventory e suas adaptações para o Brasil. In: REUNIÃO ANUAL DE PSICOLOGIA, 32., 2001, Rio de Janeiro. Anais... Rio de Janeiro: SBP, 2001. p. 84, 85.

BENEVIDES PEREIRA, Ana Maria Teresa; YAMASHITA, Danielle; TAKAHASHI, Rogério Massanobu. E os educadores, como estão? Revista Eletrônica do Mestrado Profissional em Ensino de Ciências da Saúde e do Ambiente, Araucária, v. 3, n. 3, p. 151-170, 2010.

BRASIL. Lei 11.738 de 16 de julho de 2008. Dispõe sobre o Piso Salarial Profissional Nacional do Magistério. Disponível em <http://www.planalto.gov.br/ ccivil_03/_ato2007-2010/2008/lei/l11738.htm.> Acesso em: 13 jan. 2013.

CARLOTTO, Mary Sandra. Síndrome de "Burnout": um tipo de estresse ocupacional. Canoas: Ulbra, Universidade Luterana do Brasil, 2001.

CARLOTTO, Mary Sandra; PALAZZO, Lílian dos Santos. Síndrome de burnout e fatores associados: um estudo epidemiológico com professores. Caderno de Saúde Pública, Rio de Janeiro, v. 2, n. 5, p. 1017-1026, maio 2006.

Movimento, Porto Alegre, v. 20, n. 2, p. 519-539, abr.jun. de 2014. 
CHRISTOFOLETTI, Gustavo et al. Síndrome de burnout em acadêmicos de fisioterapia. Fisioterapia e Pesquisa, São Paulo, v. 14, n. 2, p. 35-39, 2007.

CODO, Wanderley; VASQUES-MENEZES, lone. O que é burnout? In: CODO, W. (Org.). Educação: carinho e trabalho. Vozes, Petrópolis, 1999.

FARIAS, Gelcemar Oliveira; NASCIMENTO, Juarez Vieira do. Construção da identidade profissional: metamorfoses na carreira docente em Educação Física: In: NASCIMENTO, Juarez Vieira; FARIAS, Gelcemar Oliveira (Org.). Construção da identidade profissional em educação física: da formação à intervenção. Florianópolis: Ed. da UDESC, 2012. p. 61-80.

GIL, Antônio Carlos. Como elaborar projetos de pesquisa. 4. ed. São Paulo: Atlas, 2007.

GIL-MONTE, Pedro R.; PEIRÓ, José M. Desgaste psíquico em el trabajo: el síndrome de quemarse. Madrid: Sínteses, 1997.

GOMES, A. Rui et al. Stress ocupacional no ensino: um estudo com professores do $3^{\circ}$ ciclo e ensino secundário. Revista Psicologia e Sociedade, Belo Horizonte, v. 22, n. 33, p. 587-597, 2010.

GUIMARÃES, Flávia Arantes Lopes. Realização profissional, prazer, e sofrimento no trabalho: um estudo com profissionais de nível superior. 2005. 137f. Dissertação (Mestrado em Psicologia) - Instituto de Psicologia, Universidade Federal de Uberlândia, Uberlândia, 2005.

LEMOS, Carlos Augusyo Fogliarini de. Qualidade de vida na carreira profissional de professores de Educação Física do magistério público estadual/RS. 2007. 114 f. Dissertação (Mestrado em Educação Física) - Centro de Desportos, Universidade Federal de Santa Catarina, Florianópolis, 2007.

LEVY, Gisele Cristine Tenório de Machado; NUNES SOBRINHO, Francisco de Paula; SOUZA, Carlos Alberto Absalão de. Síndrome de Burnout em professores da rede pública. Revista Produção, São Paulo, v. 19, n. 3, p. 458-465, 2009. Disponível em: <http://www.scielo.br/scielo.php?script=sci_arttext\&pid=S010365132009000300004\&lng=en\&nrm=iso >. Acesso em: 3 maio 2011.

MASLACH, Cristina; JACKSON, Susan. Maslach Burnout Inventory: manual. Palo Alto, California: Consulting Psychologists, 1986.

MASLACH, Cristina; JACKSON, Susan. Patterns of burnout among a national sample of public contact workers. Journal of Health and Human Resources Administration, Montgomery, AL, v. 7,n. 2, p. 189-212, 1984.

MASLACH, Cristina; JACKSON, Susan. The measurement of experienced burnout. Journal of Occupational Behavior, Palo Alto, Califórnia, v. 2, n. 2, p. 99-113, 1981.

MASLACH, Cristina; JACKSON, Susan. The role of sex and family variables in burnout. Sex Roles, New York, v. 12, n. 7/8, p. 837-851, 1985.

Movimento, Porto Alegre, v. 20, n. 2, p. 519-539, abr.jun. de 2014. 
MASLACH, Cristina; SCHAUFELI, Wilmar; LEITER, Michael. Job burnout. Annual Review of Psychology, Palo Alto, n. 52, p. 397-422, 2001. Disponível em: <http:// www.annualreviews.org/doi/abs/10.1146/annurev.psych.52.1.397> Acesso em: 3 maio 2011.

MATTAR, Fauze Nagib. Pesquisa de marketing: metodologia e planejamento. 5. ed. São Paulo: Atlas, 1999.

MAZON, Vania; CARLOTTO, Souza Mary Sandra; CÂMARA, Sheila Gonçalves. Síndrome de Burnout e estratégias de enfrentamento em professores. Arquivos Brasileiros de Psicologia, Rio de Janeiro, v. 60, n. 1, p. 55-66, abr. 2008.

MOREIRA, Hudson de Resende et al. Qualidade de vida no trabalho e síndrome de burnout em professores de educação física do estado do Rio Grande do Sul, Brasil. Revista Brasileira de Atividade Física \& Saúde, Florianópolis, v. 14, n. 2, p. 115-122, 2009.

MUROFUSE, Neide Tiemi; ABRANCHES, Sueli Soldati; NAPOLEÃO Anamaria Alves. Reflexões sobre estresse e Burnout e a relação com a enfermagem. Revista Latino-Americana de Enfermagem, Ribeirão Preto, v. 13, n. 2, p. 255-261, mar./ abr. 2005.

NÓVOA, Antonio. Histoire e comparaison; essaissurl'éducation. Lisbonne: Educa Éditeur, 1998.

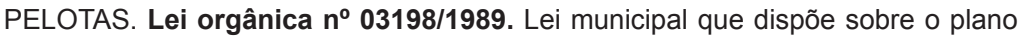
de carreira do magistério público municipal. Disponível em: <http://www.pelotas. rs.gov.br/planodecarreira/arquivos/plano_de_carreira_magisterio.pdf> Acesso em: 13 jan. 2013.

REIS, Eduardo J. F. BORGES dos et al. Docência e exaustão emocional. Educação e Sociedade, Campinas, v. 27, n. 94, p. 229-253, 2006.

RODRIGUES, Renata Marques; FIGUEIREDO, Zenólia Christina; ANDRADE FILHO, Nelson Figueiredo. Relações socioprofissionais como elemento de influência na construção das identidades docentes. Movimento, Porto Alegre, v. 18, n. 4, p.175-195, 2012.

SANTINI, Juarez. Síndrome do esgotamento profissional: revisão bibliográfica. Movimento, Porto Alegre, v. 10, n. 1, p. 183-209, 2004.

SANTINI, Juarez; MOLINA NETO, Vicente. A síndrome do esgotamento profissional em professores de educação física: um estudo na rede municipal de ensino de Porto Alegre. Revista Brasileira de Educação Física e Esporte, São Paulo, v. 19, n. 3, p. 209-222, jul./set. 2005.

SILVA JÚNIOR, Vagner Pereira da; NUNES, Paulo Ricardo Martins. Qualidade de vida, perfil demográfico e profissional de professores de Educação Física. Pensar a Prática, Goiânia, v. 12, n. 2, p. 1-11, 2009. Disponível em: <http://www.revistas. ufg.br/index.php/fef/article/view/3795/4980>. Acesso em: 28 ago. 2012.

Movimento, Porto Alegre, v. 20, n. 2, p. 519-539, abr./jun. de 2014. 
SILVA, Vannessa Monteiro Beserra da; LIMA, Naíla Kelly do Nascimento. Análise dos fatores desencadeadores da síndrome de burnout em professores da Escola Municipal Antilhon Ribeiro Soares. In: SIMPÓSIO CIÊNCIAS HUMANAS E LETRAS, 2010, Teresina. p. 1-19. Disponível em: http://www.uespi.br/prop/. Acesso em: 26 ago. 2011.

SILVA, Marta Solange Strecher Janelli; AFONSO, Mariângela da Rosa. Síndrome de Burnout em professores de Educação Física. In: FOLLE, Alexandra; FARIAS, Gelcemar Oliveira (Org.). Educação Física: prática pedagógica e trabalho docente. Florianópolis: Ed. UDESC, 2012. p. 299-318.

SINOTT, Edilene; VEIGA, Rosane Ferreira; AFONSO, Mariângela da Rosa. Síndrome de burnout: um estudo com professores de educação física da rede municipal de ensino. In: SIMPÓSIO NACIONAL DE EDUCAÇÃO FÍSICA, 2012, Pelotas. Anais... Pelotas: SNEF, 2012. p. 1-13.

TARDIF, Maurice. Saberes profissionais dos professores e conhecimentos universitários: elementos para uma epistemologia da prática profissional dos professores e suas consequências em relação à formação para o magistério. Revista Brasileira de Educação, Rio de Janeiro, v. 13, p. 5- 24, jan./abr. 2000.

THOMAS, Jerry R.; NELSON, Jack K. Métodos de pesquisa em atividade física. Porto Alegre: Artmed, 2002.

TIRONI, Márcia Oliveira Staffa et al. Trabalho e síndrome da estafa profissional (síndrome de burnout) em médico $s$ intensivistas de salvador. Revista da Associação Médica Brasileira, São Paulo, v. 55, n. 6, p. 656-62, 2009.

Endereço para correspondência:

Edilene Cunha Sinott

Rua Luís de Camões, 625 - Três Vendas

96055-630

Pelotas/RS - Brasil

Recebido em: 23.10 .2013

Aprovado em: 14.02.2014

Movimento, Porto Alegre, v. 20, n. 2, p. 519-539, abr.jun. de 2014. 